sinh viên: 56.9\%; trả lời câu hỏi trên lớp: 34.7\%; đánh giá kết quả tự học của sinh viên: $23.6 \%$

$40.3 \%$ giảng viên chỉ thực hiện kiểm tra thường xuyên 1 lần trong một hơc phần.

Có sự khác biệt trong cách tính điểm thường xuyên của các giảng viên: $88.9 \%$ : tính điểm trung bình cộng; $4.2 \%$ : lấy điểm cao nhất; 4,2\%: lấy điểm bài kiểm tra cuối cùng; $2.8 \%$ : lấy điểm ngẫu nhiên;

13.9 giảng viên không phổ biến đáp án, thang điểm, chữa bài sau khi kiểm tra TX; $29.2 \%$ giảng viên PTMH không trả bài cho SV sau khi kiểm tra TX;

$90.3 \%$ giảng viên cho rằng: cần thiết ban hành quy định đánh giá điểm thường xuyên.
TÀI LIÊU THAM KHẢO

1. Hội nghị trung ương 8 khóa XI. Nghị quyết 29

2. Thông tư số 04/2016/TT-BGDĐT ngày 14/3/2016 của Bộ trưởng Bộ Giáo dục và Đào tao Tiêu chuẩn đánh giá chẩt lượng chương trình đào tạo các trình độ của giáo dục đại hoc

3. Công văn số 1074/KTKĐCLGD-KĐĐH ngày 28 tháng 6 năm 2016 của Cục Khảo thí và Kiểm định chất lượng giáo dục hướng dẫn chung về sử dụng tiêu chuẩn đánh giá chất lượng CTĐT các trình độ của GDĐH

4. Trường Đai học Kỹ thuật Y tế Hải Dương. Báo cáo kết quả đánh giá chất lượng đề thi trắc nghiệm khách quan học phần học kỳ II năm học 2018 - 2019

5. Quyết định Số: 17/VBHN-BGDĐT, ngày 15 tháng 5 năm 2014 về việc ban hành quy chế đào tạo đại học và cao đẳng hệ chính quy theo hệ thống tín chỉ

\title{
ĐĂC ĐIỂM HÌNH THÁI HÊ THỐNG ỐNG TỦY RĂNG HÀM LỚN THỨ NHẤT HÀM TRỀN TRÊN PHIM CONEBEAM CT
}

\author{
Trương Thị Mai Anh*, Phạm Thị Thu Hiền*, \\ Đỗ Thị Thu Hương*, Phạm Như Hải*, Nguyễn Thị Như Trang**
}

\section{TÓM TẮT}

Mục tiêu: Xác định số lượng và hình thái ống tủy của rắng hàm lớn thứ nhất hàm trên trên phim Conebeam ở một nhóm người khu vực Hà Nội và lân cận. Kết quả: Phim CBCT của 334 bênh nhân đã được sử dụng. Hầu hết răng hàm lớn thứ nhất hàm trên có $(99,55 \%) ; 35,78 \%$ răng có chân gân ngoài có hệ thống ống tủy phức tạp (vertucci 2-7). Sự khác nhiau bên phải và trái khồng có ý nghĩa thống kê. Chân xa và chân trong chỉ có 1 ống tủy từ lỗ vào ống tủy đến chóp răng. Hình thái chân ngoài gần theo Vertucci I ở nữ là $71,86 \%$ cao hơn ở nam (54,97\%). Các hình thái khác không có sự khác biệt giữa nam và nữ. Hình thái ống tủy chữ C chiếm 2,99\%, trong đó hình thái $B 1(1,04 \%)$ và $C(1,2 \%)$, không có sự khác biệt giữa nam và nữ cũng như bên phải và bên trái

Tư khóa: ống tủy, nội nha, cone-beam, răng hàm lớn thứ nhất hàm trên.

\section{SUMMARY \\ MORPHOLOGIC CHARACTERISTICS OF ROOT CANALSYSTEMS IN FIRST UPPER MOLARS USING CONEBEAM COMPUTER TOMOGRAPHY}

Aims: identify morphologic characteristics of first upper molar root canal in group of people lived in

\footnotetext{
*Trường Đại học Y Dược - Đại học Quốc Gia Hà Nội **Trướng Đại Học Y Hà Nội

Chịu trách nhiệm chính: Trương Thi Mai Anh

Email: maianh7290@gmail.com

Ngày nhận bài: 13.4.2021

Ngày phản biên khoa học: 25.5.2021

Ngày duyệt bài: 11.6.2021
}

Hanoi city and nearby. Results: CBCT of 334 patients were used. Most first upper molar have 3 separate roots $(99,55 \%)$; additional canals were found in $35,78 \%$ of the mesiobuccal (MB), no difference between the right and left side. The distal and medial roots have only one canal from the canal entrance to the apex. The global prevalence of $\mathrm{C}$-shaped canal is $2,99 \%$, of which the B1-type accounts for $1,04 \%$ and C-type accounts for $1,2 \%$. No difference between male and female,

Key words: root canal, endodontic, cone-beam computed tomographic, maxillary first molars

\section{I. ĐĂT VẤN ĐỀ}

Hiểu biết kĩ càng về hình thái học tủy răng là rất quan trợng để thành công trong điều trị nội nha. Do mỗi răng đều có đặc điểm riêng, nêu tạo ra một số lượng lớn các biến thể về số lượng và hình thái ống tủy. Những đặc điểm này làm khó khăn trong việc tạo hình, làm sạch và trám bít hệ thống ống tủy ba theo 3 chiều không gian, là tam thức để thành công trong điều trị nội nha.

Mặt khác, sự hiểu biết không chính xác về tính phức tạp của hình thái ống tủy luôn dẫn đến không có phương pháp và cách thức tạo hình ông tủy phù hợp. Các thông số giải phẫu thường được mô tả trong tài liệu là răng hàm trên thứ nhất có 3 chân răng và 3 ống tủy mà không nêu ra được các biến thể có thể gặp cũng như tỷ lệ để các bác sĩ lâm sàng cẩn trọng khi điều trị tủy cho bệnh nhân, dễ dẫn tới điều trị sót ônng tủy.

Chụp cắt lớp vi tính chùm tia hình nón (CBCT) 
giúp tạo ra hình ảnh 3 chiều của các cấu trúc được chụp, có giá trị cao trong đánh giá hình thái hê thống ống tủy cần trong điều trị nội nha. Mục đích của nghiên cứu này là xác định hình thái của ống tủy răng hàm lớn thứ nhất hàm trên, là răng có hệ thống ống tủy phức tạp nhất trong bộ răng.



Hình 1: trường hợp chân gần răng 16 có 2 ông tưy

Nguồn: F. Somma (2008) "Root canal morphology of the mesiobuccal root of maxillary first molars: $A$ micro-computed tomographic analysis"

\section{II. ĐốI TƯƠ'NG VÀ PHƯƠNG PHÁP NGHIÊN CỨU}

2.1 Đối tượng: Mẫu nghiên cứu gồm 334 răng hàm lớn thứ nhất hàm trên bên phải và trái của 334 phim conebeam CT của bệnh nhân Hà Nội và vùng lân cận, gồm 151 nam và 182 nữ, tuổi từ 18 đến 45 tuối, độ tuổi trung bình là $26,77 \pm 8,06$.

Tiêu chuẩn chọn mẫu:

- Có đủ 2 răng hàm lớn thứ nhất hàm trên

- Các răng hàm lớn thứ nhất hàm trên có chân răng phát triển hoàn toàn

- Hình ảnh conebeam CT rõ ràng, thể hiện được hình ảnh các ống tủy.

Tiêu chuẩn loại trừ: Các răng hàm lớn thứ nhất hàm trên đã bị

- Tiêu ngót chân răng

- Trám bít hoặc có miếng trám đến tủy

- Phục hồi kim loại như chốt, mão

- Nghiêng hoặc mọc ngầm

\section{Cỡ mẫu}

$$
\mathrm{n}=\frac{\mathrm{Z}^{2}-\alpha_{/ 2} \mathrm{P}(1-\mathrm{P})}{\mathrm{d}^{2}}
$$

Răng cối lớn thứ nhất hàm trên: dựa vào kết quả nghiên cứu của Wolf1 Thomas Gerhard (2017), tỉ lệ chân gần ngoài răng cối lớn thứ nhất hàm trên có $\geq 2$ ống tủy là $68 \%$ [1]. Áp dụng vào công tức tính cỡ mẫu:
Độ tin cậy 95\%, Z (1- a/2) =1,96; d=0,05 Cõ mẫu tối thiểu là 334 răng

2.2 Phương pháp nghiên cứu: Nghiên cứu thực hiện theo thiết kế cắt ngang mô tả phân tích trên conebeam $\mathrm{CT}$. Bệnh nhân này đã được chụp conebeam CT bằng máy Galileos (Sirona Dental System Inc., Đức), kích cõ voxel $0,3 \mathrm{~mm} x$ $0,3 \mathrm{~mm} \times 0,3 \mathrm{~mm}$, Gray scale 12 bit tại Bộ môn Chẩn đoán Hình ảnh, Đại học Y dược-Đại Học Quốc Gia Hà Nội và phòng chụp Xquang Hà Thành trong khoảng thời gian từ tháng 6 năm 2019 đến tháng 4 năm 2021.

Quan sát hình ảnh bằng phần mềm Galileos Viewer (Sirona Dental System Inc.) trên màn hình 24 inch có độ phân giải $1.920 \times 1.200$, độ tương phản $1.000: 1$, bề dày mỗi lát cắt $1 \mathrm{~mm}$. Trình tự thực hiện như sau:

Hình thái ống tủy: được ghi nhận theo phân loại Vertucci $(1984)[2,3]$. Những ống tủy có hình thái khác ngoài phân loại Vertucci được ghi nhận theo số ống tủy thay đổi theo chiều dài chân răng từ cổ đến chóp.

Hình thái ống tủy ghi nhận theo phân loại Vertucci gồm 8 loại (hình 3):

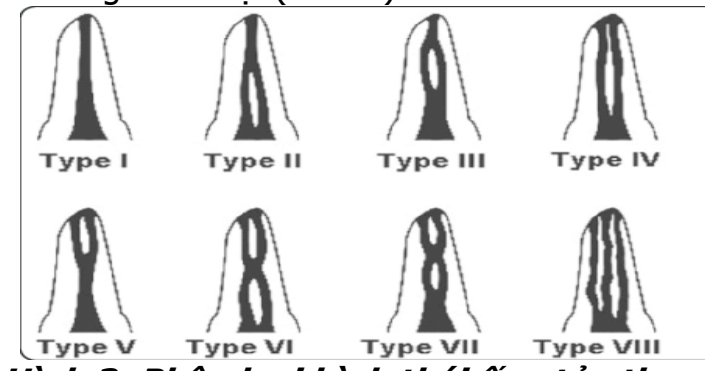

Hình 3: Phân loại hinh thái ống tủy theo Vertucci. Nguồn: Vertucci FJ (2005).

Loại I: chỉ có một ống tủy từ buồng tủy đến lỗ chóp chân răng.

Loại II: có hai ống tủy xuất phát từ buồng tủy tạo thành hai ống tủy riêng biệt nhưng gặp nhau ở gần chóp để thành một ống tủy và ra khỏi chân răng bằng một lỗ chóp.

Loại III: có một ống tủy xuất phát từ buồng tủy nhưng sau đó chia hai và gặp nhau ở gần chóp để tạo một ống tủy và ra khỏi chân răng bằng một lỗ chóp.

Loại IV: có hai ống tủy riêng biệt kéo dài từ buồng tủy tới chóp chân răng.

Loại V: một ống tủy xuất phát từ buồng tủy, sau đó tách ra thành hai ống tủy và đi khỏi chân răng bằng hai lỗ chóp riêng biệt.

Loại VI: hai ống tủy xuất phát từ buồng tủy, kết hợp lại thành một ống tủy và sau đó lại chia hai ở chóp với hai lỗ chóp riêng biệt.

Loại VII: một ống tủy xuất phát từ buồng tủy, 
chia hai sau đó kết hợp lại thành một ống tủy và lại chia hai ở chóp với hai lỗ chóp riểng biệt.

Loại VIII: có ba ống tủy riêng biệt kéo dài từ buồng tủy đến chóp chân răng.

Ông tủy hinh C: khi các ống tủy hợp lại với nhau tạo thành 1 ống tủy dạng dải cong, hình chữ $\mathrm{C}$. Ống tủy hình $\mathrm{C}$ được quan sát trong thiết diện cắt ngang để ghi nhận hình thái và số lượng ống tủy ở từng phân ba chân răng: phần ba cổ, phần ba giữa và phần ba chóp. Ông tủy hình $C$ được ghi nhận theo phân loại của Martin (2016) [4](hình 4 và 5 ).



Hình 4: Phân loại ống tưy hình C ở răng côii lớn hàm trên dựa vào vị trí các ống tửy Nguồn: Martins, (2016).

Phương pháp xử lý số liệu: Xử lý số liệu bằng phần mềm thống kê SPSS 24

III. KẾT QUẢ NGHIÊN CỨU

3.1. Xác định số lượng và hình thái ống tủy của răng hàm lớn thứ nhất hàm trên trên phim Conebeam ở người khu vực Hà Nội và lân cận.

3.1.1 Số lượng chân răng hàm lớn thử nhất hàm trên hàm trên

Bảng 1: Số lượng chân răng hàm lớn thứ nhất hàm trên

\begin{tabular}{|c|c|c|c|c|c|}
\hline Số lượng chần & Răng 16 & Răng 26 & P & Tống & Tỷ lệ \\
\hline 2 chân & 1 & 2 & 1 & 3 & $0,45 \%$ \\
\hline 3 chân & 333 & 332 & 1 & 665 & $99,55 \%$ \\
\hline Tống & $\mathbf{3 3 4}$ & $\mathbf{3 3 4}$ & & $\mathbf{6 6 8}$ & \\
\hline
\end{tabular}

Số lượng chân răng 2 bên phải và trái khác biêt nhau không có ý nghĩa thống kê. Chủ yếu là 3 chân răng chiếm 99,55\%, răng 2 chân $(0,45 \%)$ rất ít gặp.

3.1.2 Hình thái ống tủy chân gân ngoài của răng hàm lớn thứ nhất hàm trên theo Vertucci

Bảng 2: Hình thái ống tủy chân gânn ngoài của răng 6 theo Vertucci

\begin{tabular}{|c|c|c|c|c|c|}
\hline Hình thái ống tủy & Răng 16 & Răng 26 & P & Tống & Tỷ lệ \\
\hline Loại I theo Vertucci & 208 & 221 & 0,53 & 429 & $64,22 \%$ \\
\hline Loại II theo Vertucci & 63 & 46 & 0,103 & 109 & $16,32 \%$ \\
\hline Loại III theo Vertucci & 2 & 3 & 0,655 & 5 & $0,75 \%$ \\
\hline Loại IV theo Vertucci & 47 & 55 & 0,428 & 102 & $15,27 \%$ \\
\hline Laại V theo Vertucci & 7 & 6 & 0,782 & 13 & $1,95 \%$ \\
\hline Loại VI theo Vertucci & 5 & 2 & 0,257 & 7 & $1,04 \%$ \\
\hline Loại VII theo Vertucci & 2 & 1 & 0,564 & 3 & $0,45 \%$ \\
\hline Loại VIII theo Vertucci & - & - & - & - & - \\
\hline & 334 & 334 & & 668 & \\
\hline
\end{tabular}

Chân gần ngoài răng hàm lớn thứ nhất hàm trên chủ yếu có 1 ống tủy thắng từ trên xuống (vertucci I) chiếm 64,22\%. Sự khác nhau bên phải và trái không có ý nghĩa thống kê. Chân xa và chân trong chỉ có 1 ống tủy từ lỗ vào ống tủy đên chóp răng (loại I Vertucci)

3.1.3 Hinh thái ống tưy hình chữ C răng hàm lớn thứ nhất hàm trên

Bảng 3: Hình thái ống tưy hình chữ C răng hàm lớn thứ nhất hàm trên

\begin{tabular}{|c|c|c|c|c|c|}
\hline Hình thái & Răng 16 & Răng 26 & $\mathbf{P}$ & Tống & Tỷ lệ \\
\hline A & 2 & - & - & 2 & $0,3 \%$ \\
\hline B1 & 2 & 5 & 0,257 & 7 & $1,04 \%$ \\
\hline B2 & - & - & - & - & $0 \%$ \\
\hline D & 4 & 4 & 1 & 8 & $1,2 \%$ \\
\hline E1 & - & - & - & - & - \\
\hline E2 & 1 & 1 & 1 & 2 & $0,3 \%$ \\
\hline & 1 & - & - & 1 & $0,15 \%$ \\
\hline
\end{tabular}

Trong số 668 răng 6 hàm trên 2 bên thì có 10 răng 16 và 10 răng 26 có hình thái ống tủy chữ $C$ 
chiếm $2,99 \%$, trong đó hình thái $B 1(1,04 \%)$ và $C(1,2 \%)$ chiếm tỷ lệ cao nhất. Sự khác biệt về hình thái 2 bên không có ý nghĩa thống kê

3.2 Mối liên quan giới tính với hình thái chân răng hàm lớn thứ nhất hàm trên

3.2.1 Số lượng chân răng hàm lớn thứ nhất hàm trên hàm trên

Bảng 4 Mối liên quan giữa giới tính với số lượng chân răng

\begin{tabular}{|c|c|c|c|c|c|}
\hline Số lượng chân răng & Nam & Tỷ lệ & Nữ & Tỷ lệ & P \\
\hline 2 chân & 2 & $0,66 \%$ & 1 & $0,27 \%$ & \multirow{2}{*}{0,592} \\
\hline 3 chân & 300 & $99,34 \%$ & 365 & $99,73 \%$ & \\
\hline Tống & 302 & & 366 & & \\
\hline
\end{tabular}

Số lượng răng 6 trên có 3 chân ở nam $(99,34 \%)$ ít hơn nữ $(99,73 \%)$ nhưng số lượng răng 6 hàm trên ở nữ có 2 chân $(0,66 \%)$ lại nhiêu hơn nam $(0,27 \%)$, khác biệt không có ý nghĩa thống kê $(p>0,05)$

3.2.2 Hình thái chân răng gân ngoài theo Vertucci

Bảng 5: Mối liên quan giữa giới tính với hình thái chân răng gân ngoài

\begin{tabular}{|c|c|c|c|c|c|}
\hline Hình thái chân răng & Nam & Tỷ lệ & Nữ & Tỷ lệ & P \\
\hline Loại I theo Vertucci & 166 & $54,97 \%$ & 263 & $71,86 \%$ & $\mathbf{0 , 0 0 0}$ \\
\hline Loại II theo Vertucci & 60 & $19,87 \%$ & 49 & $13,39 \%$ & 0,292 \\
\hline Loại III theo Vertucci & 4 & $1,32 \%$ & 1 & $0,27 \%$ & 0,180 \\
\hline Loại IV theo Vertucci & 59 & $19,54 \%$ & 43 & $11,75 \%$ & 0,113 \\
\hline Loại V theo Vertucci & 7 & $2,32 \%$ & 6 & $1,64 \%$ & 0,782 \\
\hline Loại VI theo Vertucci & 3 & $0,99 \%$ & 4 & $1,09 \%$ & 0,705 \\
\hline Loại VII theo Vertucci & 3 & $0,99 \%$ & - & - & - \\
\hline Loại VIII theo Vertucci & - & - & - & - & - \\
\hline Tống & 302 & & 366 & & \\
\hline
\end{tabular}

Hình thái chân ngoài gân có 1 ống tủytủy (Vertucci I) ở nữ là 71,86\% cao hơn ở nam (54,97\%).

Các hình thái khác không có sự khác biêt giữa nam và nữ

3.2.2 Hinh thái ống tưy hinh chữ C răng 7

Bảng 6: Mối liên quan giứa giới tính với hinh thái ống tủy chữ C

\begin{tabular}{|c|c|c|c|c|c|}
\hline Hình thái & Nam & Tỷ lệ \% & $\mathbf{N u \tilde { u }}$ & Tỷ lệ & $\mathbf{P}$ \\
\hline A & 1 & 7,14 & 1 & 16,67 & 0,705 \\
\hline B1 & 3 & 21,4 & 4 & 66,66 & 0,705 \\
\hline B2 & 0 & 0 & 0 & 0 & - \\
\hline D & 7 & 50 & 1 & 16,67 & $\mathbf{0 , 0 3 4}$ \\
\hline E1 & 0 & 0 & 0 & 0 & - \\
\hline E2 & 2 & 14,28 & 0 & 0 & - \\
\hline Tống số răng có hình chữ C & 1 & 7,14 & 0 & 0 & - \\
\hline Tổng số răng theo giới & 320 & & 6 & & 0,87 \\
\hline
\end{tabular}

Hình thái ống tủy $C$ hay gặp ở nam $(4,38 \%)$ hơn nữ $(1,5 \%)$, khác biệt không có ý nghĩa thống kê $p>0,05$. Loại $C$ gặp ở nam nhiều hơn nữ, các hình thái khác không có sự khác biệt.

\section{BÀN LUẬN}

Trong số 668 răng 6 hàm trên nghiên cứu thì chúng tôi nhận thấy chủ yếu là 3 chân răng chiếm 99,55\%. Số lượng chân răng 2 bên phải và trái khác biệt nhau không có ý nghĩa thống kê. Tỷ lệ này tương tự với nghiên cứu của Huỳnh Hữu Thục Hiền trên người dân thành phố Hồ Chí Minh là 99,7\%[5]. Một vài nghiên cứu khác cũng trên người châu Á cung cho kết quả răng 6 hàm trên có 3 chân răng riêng biệt là phổ biến rất hiếm găp các biến thể về hình thái và số lượng chân răng như nghiên cứu của Zhang $\mathrm{R}$ trên người Trung Quốc [6] nghiên cứu của Alavi AM trên người Thái Lan [7] và của Kim Y trên người
Hàn Quốc [8].

Về hình thái ống tủy chân răng trong nghiên cứu của chúng tôi thì các chân răng chỉ có 1 ống tủy, riêng ống ngoài gần có hệ thống ống tủy phức tạp, chỉ có $64,22 \%$ có 1 ống tủy. Tỷ lệ này cao hơn nhiêuu so với nghiên cứu của Huỳnh Hữu Thục Hiền[5] sự khác biêt này có thể do sự đa dạng và phức tạp của hệ thống ống tủy gần ngoài, ngoài ra còn ảnh hưởng bởi mẫu nghiên cứu, cách chọn răng vào mẫu nghiên cứu. Tỷ lệ chân gần ngoài ống tủy dạng I, II, IV là phổ biến nhất. Khi so sánh với các nghiên cứu ở châu Á khác, kết qủa nghiên cứu tương tự với người Thái Lan, các dạng loại IV, I và II thường gặp và 
chiếm tỉ lệ cao[7]. Còn ở người Nhật, các dạng loại I, II, IV, V và VI là thường gặp[9]. Trong khi ở người Trung Quốc, loại I là thường gặp nhất, tiếp đến là loại IV, II và V [6]. Điều này có thể do đăc điểm giải phẫu của người Việt Nam.

Hình thái chân ngoài gân theo Vertucci I ở nứ là $71,86 \%$ cao hơn ở nam (54,97\%). Các hình thái khác không có sự khác biệt giữa nam và nữ.

Bảng 8: Hình thái ống tủy ngoài gân răng 6 trên theo Vertucci

\begin{tabular}{|c|c|c|c|c|c|c|c|c|c|c|c|}
\hline Nghiên cứu & Quốc gia & $\begin{array}{c}\text { N } \\
\text { (răng) }\end{array}$ & Loại I & $\begin{array}{c}\text { Loại } \\
\text { II }\end{array}$ & $\begin{array}{c}\text { Loaai } \\
\text { III }\end{array}$ & $\begin{array}{c}\text { Loaíi } \\
\text { IV }\end{array}$ & $\begin{array}{c}\text { Loại } \\
\text { V }\end{array}$ & $\begin{array}{c}\text { Loại } \\
\text { Vi }\end{array}$ & $\begin{array}{c}\text { Loại } \\
\text { VII }\end{array}$ & $\begin{array}{c}\text { Loaii } \\
\text { VIII }\end{array}$ & $\begin{array}{c}\text { Loái } \\
\text { khác }\end{array}$ \\
\hline Zhang 2011 [6] & Trung Quốc & 299 & 48 & 7,3 & - & 36,4 & 8,3 & - & - & - & - \\
\hline Neelakantan 2010 & Ân Đố & 220 & 51,8 & 5,5 & - & 38,6 & - & - & - & - & 1 \\
\hline Lee 2011 & Hàn Quốc & 458 & 28,2 & 33,2 & 34,9 & 2,4 & 1,3 & - & - & - & - \\
\hline Kim 2012 [8] & Hàn Quốc & 802 & 36,4 & 20,5 & 0,25 & 40,7 & 2 & 0,12 & - & - & 0,12 \\
\hline Guo 2014 & Hoa Kỳ & 628 & 28,3 & 26,3 & 1,1 & 41,9 & 2,4 & - & - & - & - \\
\hline $\begin{array}{c}\text { Huỳnh HT Hiền } \\
\text { 2019 [5] }\end{array}$ & Việt Nam & 763 & 32,2 & 14,5 & 2,6 & 35,3 & 12,1 & 1,31 & 0,1 & 0,4 & 1,6 \\
\hline
\end{tabular}

Hình thái ống tủy chữ $\mathrm{C}$ trong nghiên cứu của chúng tôi chiếm 2,99\%, trong đó hình thái $\mathrm{B} 1$ $(1,04 \%)$ và $C(1,2 \%)$ chiếm tỷ lệ cao nhất, lớn hơn so với nghiên cứu của Martins ] [4] ở người Bồ đào nha trên phim conebeam chỉ có $1,1 \%$ trong tổng số 918 răng, với các loại hình thái chữ $C$ theo Bảng 9, trong đấy chiếm nhiều nhất là loại B1 tương tự như nghiên cứu của chúng tôi. Và biến thể chữ $C$ cũng hay gặp ở nam hơn nữ

Bảng 9: So sánh tỷ lệ \% ống tủy chữ C ở răng 7 hàm trên của Martins

\begin{tabular}{|c|c|c|c|c|c|c|c|c|c|}
\hline Của Martins J & $\begin{array}{c}\text { Khônng } \\
\text { có }\end{array}$ & Loại A & Loại B1 & Loại B2 & Loại C & Loại D & Loại E1 & $\begin{array}{c}\text { Loại } \\
\text { E2 }\end{array}$ & Tổng \\
\hline Số lượng & 918 & 1 & 1 & 0 & 8 & 0 & 0 & 0 & 928 \\
\hline Tỳ lệ \% & 98,9 & 0,1 & 0,1 & 0 & 0,9 & 0 & 0 & 0 & $100 \%$ \\
\hline \multicolumn{8}{|c|}{ Của chúng tôi } \\
\hline Số lượng & 658 & 2 & 7 & 0 & 8 & 0 & 2 & 1 & 668 \\
\hline Tỷ lẹ̣ \% & 2,99 & 0,3 & 1,04 & 0 & 1,2 & 0 & 0,3 & 0,15 & $100 \%$ \\
\hline
\end{tabular}

\section{KẾT LUÂN}

Răng 6 trên thường có 3 chân $(99,55 \%)$, ít khi 2 chân $(0,45 \%)$. Số lượng chân răng ở nam và nữ không có sự khác biệt. Số lượng chân răng không khác biệt theo giới tính cũng như bên phải và bên trái.

Chân gần ngoài răng hàm lớn thứ nhất hàm trên chủ yếu có 1 ống tủy thẳng từ trên xuống (vertucci I) chiếm $64,22 \%$, tỷ lệ này ở nữ lớn hơn ở nam có ý nghĩa thống kê. Sự khác nhau bên phải và trái không có ý nghĩa thống kê. Chân xa và chân trong chỉ có 1 ống tủy từ lồ vào ống tủy đến chóp răng (loại I Vertucci)

Hình thái ống tủy chữ $C$ chiếm 2,99\% số răng hàm lớn thứ nhất hàm trên nghiên cứu, trong đó hình thái $B 1(1,04 \%)$ và $C(1,2 \%)$ chiếm tỷ lệ cao nhất. Nam giới có tỷ lệ ống tủy chữ $C$ loại $C$ cao hơn nữ giới.

LờI CẢM ON. Chúng tôi xin cảm ơn bộ môn Răng Hàm Mặt - Trường Đại Học Y Dược ĐHQGHN, đã tạo điều kiện cơ sở vật chất và đối tượng nghiên cứu để hoàn thành đề tài.

\section{TÀI LIẸU THAM KHẢO}

1. Woif, T.G., et al., Root canal morphology and configuration of 123 maxillary second molars by means of micro-CT. Int J Oral Sci, 2017. 9(1): p. 33-37.
2. VERTUCCI, F.J., Root canal morphology and its relationship to endodontic procedures. Endodontic Topics, 2005. 10, : p. 3-29.

3. Bansal, R., S. Hegde, and M.S. Astekar, Classification of Root Canal Configurations: A Review and a New Proposal of Nomenclature System for Root Canal Configuration. Journal of Clinical and Diagnostic Research, 2018.

4. Martins, J.N., et al., Prevalence and Characteristics of the Maxillary C-shaped Molar. J Endod, 2016. 42(3): p. 383-9.

5. Hiền, H.H.T., Đắc Điểm Hình Thái Chân Răng Và Ông Tủy Răng Cổi Lớn Thứ Nhất Và Thứ Hai Người Việt Luận án tiến sĩ, Răng Hàm Mặt, Đại học Y dược TP Hồ Chí Minh, 2019.

6. Zhang, R., et al., Use of CBCT to identify the morphology of maxillary permanent molar teeth in a Chinese subpopulation. Int Endod J, 2011. 44(2): p. 162-9.

7. Alavi, A.M.v.c.C.S., Root and canal morphology of Thai maxillary molars. Int Endod J., 2002. 35(5): p. tr. 478-85.

8. Kim, Y., S.J. Lee, and J. Woo, Morphology of maxillary first and second molars analyzed by cone-beam computed tomography in a korean population: variations in the number of roots and canals and the incidence of fusion. J Endod, 2012. 38(8): p. 1063-8.

9. R, P., Root and canal morphology of human permanent teeth in a Sri Lankan and Japanese population. Anthropological Science, 2008. 116(2): p. 123-133. 